Winda Pratiwi ${ }^{1}$

Zulkifli $\mathrm{N}^{2}$

Yeni Solfiah ${ }^{3}$

\title{
HUBUNGAN KOMPETENSI KEPRIBADIAN GURU DENGAN KEDISIPLIAN GURU DI TK DURI KECEMATAN MANDAU KABUPATEN BENGKALIS
}

\begin{abstract}
Abstrak
Penelitian ini bertujuan untuk mengetahui Hubungan Kompetensi Kepribadian Guru dengan Kedisiplinan Guru di TK Duri Kecamatan Mandau Kabupaten Bengkalis. Kompetensi guru merupakan salah satu tolak ukur keberhasilan pedidikan yang dilakasanakan, dan kepribadian guru adalah cermin dalam sikap dan perbuatan guru dalam membina dan membimbing anak didiknya. Sedangkan kedisiplinan guru merupakan sifat dari pertanggung jawab individu untuk melaksanakan segala sesuatunya dengan tepat waktu. Adapun jumlah populasi ini adalah 45 orang guru dengan sampel 45 0rang guru digunakan yaitu korelasi person product moment untuk melihat hubungan variabel kompetensi kepribadian guru dengan kedisiplinan guru. Teknik pengumpulan data yaitu berapa angket dengan mengunakan skala likert. Teknik analisa data menggunakan ujicoba skala dan analisa metode statistik dengan program SPSS for windows ver.23. berdasarkan hasil yang positif dan signifikan antara kompetensi kepribadian guru dengan kedisiplinan guru di TKDuri kecamatan Mandau kabupaten Bengkalis. Hal ini dapat diketeahui dari nilai koefesien sebesar $r x y=0,031$ dan taraf signifilkasi $0,000<0,05$ tingkat hubungan kompetensi kepribadian guru dengan kedisiplinan guru sedang dengan nilai koefesien determinan yang dihasilkan sebesar $80 \%$ kedisiplinan guru.
\end{abstract}

Kata Kunci: Kompetensi Kepribadian Guru dengan Kedisiplinan Guru.

\begin{abstract}
This study to determine the relationship between the relatonship competence and discipline of teachers in Tk Duri ,Mandau sub-district Bengkalis district. The teacher is one of the benchmars for the succes of eduction implemented, and the taecher's personality is a reflection of the teacher's attitude and actions in fostering and guiding their students. Mean while teacher discipline is a charcteristic of individul responsibility to do things in a timely manner. The total population used is 45 teacher's and sampel of 45 teachers using a saturade sampel. The method used is the person product moment correlation to see the relationship between teacher variables and teacher discipline. The data colletion teachique is a quetionnaire using a likert skala. Based on positive and significant results between teacher personality competencies an teacher discipline in Tk Duri, Mandau district, Bengkalis district. This can be seen from the coefficient value of $\mathrm{rxy}=0,31$ and the significane level of $0,000<0,05$. The level of relationship between teacher personality competence and teacher discipline is in the modurate category of $80 \%$ of teacher disciplin.
\end{abstract}

Keywords: Personal Competence and Discipline

\footnotetext{
${ }^{1,2,3)}$ Porgram Studi Pendidikan Guru Pendidikan Anak Usia Dini, Fakukltas Keguruan dan Ilmu Pendidikan, Universitas Riau

Alamat email yeni.solfiah@lecturer.unri.ac.id
} 


\section{PENDAHULUAN}

Dunia pendidikan sedang mengalami berbagai perubahan sesuai dengan tuntutan dan kebutuhan masyarakat, serta ditantang untuk menjawab berbagai permasalahan lokal dan global yang terjadi begitu pesat. Perubahan dan permasalahan tersebut menurut Professor Sanusi mencakup social change, turbulence, complexity, and chaos, seperti pasar bebas (free trade), tenaga kerja bebas (free labour), perkembangan masyarakat informasi, serta perkembangan ilmu pengetahuan, teknologi, seni, dan budaya yang sangat dahsyat. Bersamaan dengan itu bangsa Indonesia sedang dihadapkan pada fenomena yang sangat dramatis, yakni rendahnya daya saing sebagai indikator bahwa pendidikan belum mampu menghasilkan sumber daya manusia (SDM) yang berkualitas (Mulyasa, 2011).

Faktor yang mempengaruhi keberhasilan Pendidikan Anak Usia Dini (PAUD), antara lain guru/pendidik, peserta didik, sarana dan prasarana, lingkungan pendidikan, dan kurikulum. Dari berbagai faktor tersebut, guru/pendidik AUD pada kegiatan proses pembelajaran menempati kedudukan yang sangat penting dan tanpa mengabaikan faktor penunjang yang lain, guru/pendidik sebagai subyek pendidikan sangat menentukan keberhasilan Pendidikan Anak Usia Dini (PAUD).

Guru merupakan komponen paling menentukan dalam sistem pendidikan secara keseluruhan yang harus mendapat perhatian sentral, pertama, dan utama. Figur yang satu ini akan senantiasa menjadi sorotan strategis ketika berbicara masalah pendidikan. Guru merupakan sumber daya manusia yang menjadi perencanaan, pelaku dan penentu tercapainya tujuan pendidikan (Marzuki, 2007). Maka UNESCO (United Nations Education, Scientific and Cultural Organization) menerapkan dan mengkampanyekan program pendidikan sepanjang hayat (lifelong education), pendidikan untuk semua (education for all), dan semua untuk pendidikan (all for education).

Standar kompetensi guru adalah ukuran yang ditetapkan atau dipersyaratkan dalam bentuk penguasaan pengetahuan dan perilaku perbuatan bagi seorang guru agar berkelayakan untuk menduduki jabatan fungsional sesuai dengan bidang tugas, kualifikasi dan jenjang pendidikan. Dalam dunia pendidikan, kompetensi adalah kemampuan yang dapat dilakukan seorang guru. Kompetensi mencakup tiga aspek, yaitu pengetahuan, sikap, dan keterampilan Sebagai suatu profesi, terdapat sejumlah kompetensi yang harus dimiliki.

Guru yang profesional dituntut agar dapat menyampaikan materi pelajaran dengan baik, efektif dan efisien sehingga siswa sebagai peserta didik dapat mengerti dan memahami apa yang disampaikan oleh guru dalam proses pembelajaran. Guru juga dituntut untuk menguasai strategi pembelajaran agar proses pembelajaran didalam kelas bergairah dan menyenangkan, selain itu guru juga diharapkan disiplin dalam melaksanakan tugasnya sebagai pendidik.

Sikap kedisiplinan adalah untuk mengarahkan mengontorol diri, selain itu juga agar dapat melalukan aktivitas terarah sesuai dengan peraturan yang dan mematuhi ketentuan norma dalam menuai tugas dan tanggung jawab. Kedisiplinan adalah setiap perseorang dan juga kelompok yang menjamin adanya kepatuhan terhadap peraturan dan perintah, dan pengunaan waktu secara afektif, ketaatan terhadap peraturan yang telah ditetapkan, datang dan pulang tepat waktu. Disiplinan adalah tindakan yang menujukkan perilaku tertib dan patuh pada berbagai ketentuan dan peraturan, orang disiplinan adalah orang teguh didalam memangang aturan, misalnya disiplinan dalam perkerjaannya yang terlihat dari masuk daan keluarnya tepat waktu, senantiasa mengikuti norma dan peraturan yang berlaku ( Sulistyowati,2012).

Menurut Siti Rimang (2012), kompetensi secara dapat diartikan kemampuan. Tentang pengertian kompetensi, terdapat beberapa defenisi, kompetensi merupakan kemampuan pengetahun dan keterampilan. Kompetesnsi juga dapat diartikan sebagai pengetahuan, keterampilan dan nilai-nilai dasar yang direfleksikan dalam kebiasaan berpikir dan bertindak. Sedangkan kepribadian menurut Witheringto, ialah seluruh tingkah laku seseorang yang intergarasikan. Sebagaimana yang tampak pada orang lain. Kepribadian ini bukan hanya yang 
melekat pada diri seseorang, tetapi lebih merupakan hasil daripada suatu pertumbuhan yang dalam suatu lingkungan.

\section{METODE}

Penelitian ini adalah penelitian kuantitatif dengan jenis penelitian korelasi yang dilanjutkan dengan menghitung besarnya hubungan Kompetensi Kepribadian Guru dengan Kedisiplinan Guru di TK duri Kecematan Mandau Kabupaten Bengkalis.

Sebelum melakukan analisis dengan teknik peason product moment melalui program spss statistic ver.23 terlebih dahulu dilakukan uji asumsi. Uji asumsi ini meliputi uji normalitas. Homogenitas dan uji lineraritas, tujuan di lakukan asmusi ini adalah agar dapat mengetahui apakah syarat -syarat untuk melakukan uji hipotesis dengan menggunakan peason product moment dapat memberikan hasil yang dapat memjawab hipotensis, dengan maksud agar dapat kesimpualan yang diperoleh tidak menyimpang dari kebenaran yang seharus diperoleh.

Teknik analisis data merupakan kegiatan yang dilakukan oleh penelitian setelah dari seluruhnya responden terkumpul. Data yang belum ada dapat diartikan, maka langkah selajutnya adalah menganalisis data.

$$
P=\frac{F}{N} \times 100
$$

Dari rumus diatas, didapatkan sampel penelitian berjumlah 45 orang.

Penelitian ini bertujuan untuk mengetahui hubungan variabel $\mathrm{X}$ dengan variabel Y. Data yang didapatkan akan dianalisis dengan metode statistik. Data yang didapatkan belum dapat diartikan. sehingga untuk memperoleh kesimpulan maka data tersebut harus diolah. Adapun untuk menganalisis data yang diperoleh peneliti menggunakan teknik korelasi Person Product Moment. Dengan rumus sebagai berikut.

$$
\frac{n\left(\sum X Y\right)-\left(\sum X\right) \cdot\left(\sum Y\right)}{\sqrt{\left[n \cdot \sum X^{2}-\left(\sum X\right)^{2}\right]} \cdot\left[n \cdot \sum Y^{2}-\left(\sum Y\right)^{2}\right]}
$$

Sebelum dilakukan analisis, terlebih dahulu dilakukan uji asumsi berupa uji normalitas, uji linieritas, uji homogenitas dan uji hipotesis.

\section{HASIL DAN PEMBAHASAN}

Pengukuran terhadap kompetensi kepribadian guru di TK Duri Kecamatan Mandau Kabupaten Bengkalis menggunakan 30 butir pertanyaan. Skor tertinggi untuk setiap guru diberi skor 5 dan terendah diberi skor 1 serta disebarkan kepada 45 orang sampel. Gambaran mengenai kepribadian guru.

\begin{tabular}{|c|c|c|c|c|c|c|}
\hline No & Indikator & Jumlah item & Skor faktul & Skor idel & persentase & katagori \\
\hline & $\begin{array}{l}\text { 1. Norma dan } \\
\text { sosial }\end{array}$ & 5 & 2 & 193 & $23,31 \%$ & \\
\hline & $\begin{array}{l}\text { 2. Sifat dewasa, } \\
\text { mandiri,dan } \\
\text { etos kerja baik }\end{array}$ & ik & 2 & 169 & $26,62 \%$ & \\
\hline & $\begin{array}{l}\text { 3. Wibawa dan } \\
\text { arif bijaksana }\end{array}$ & $a$ & 2 & 160 & $28,12 \%$ & \\
\hline & $\begin{array}{l}\text { 4. Akhlak mulai } \\
\text { dan teladan }\end{array}$ & i & 2 & 144 & $31,25 \%$ & \\
\hline
\end{tabular}

Tabel 4.4 Skor Indikator Variabel Kompetensi Kepribadian 


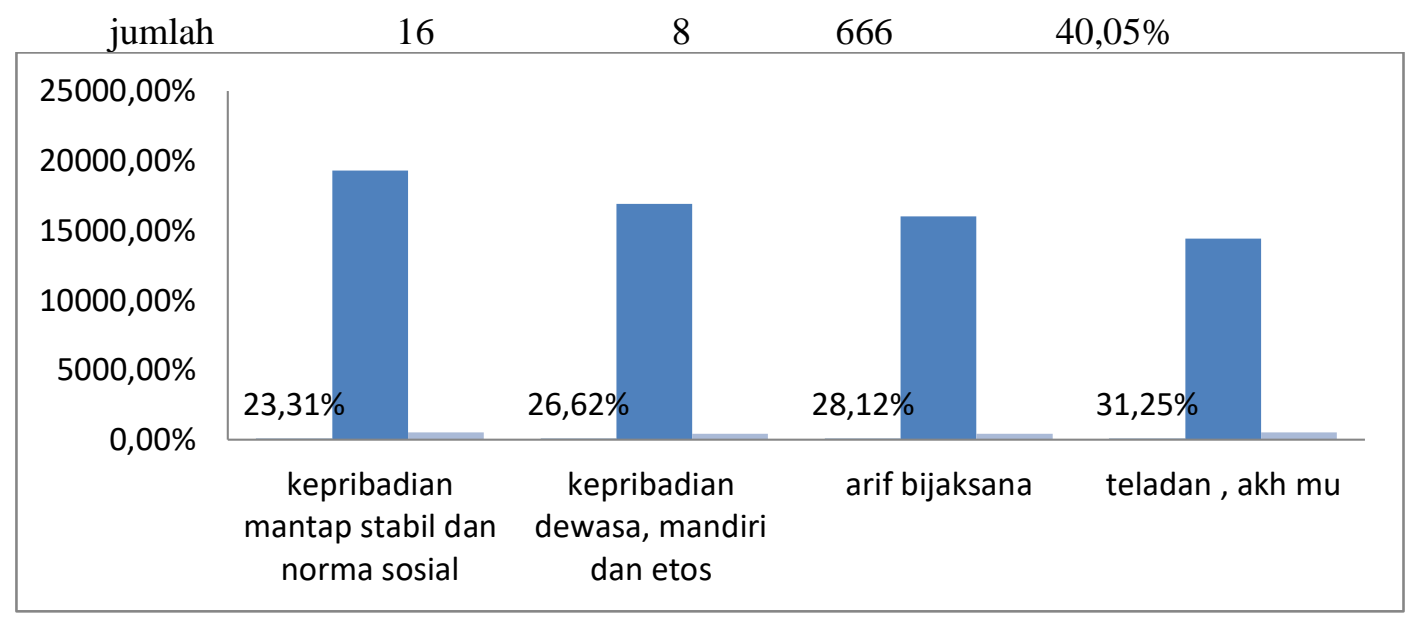

\section{Gambar 4.2 grafik Persentase Data kompetensi kepribadian guru Tk duri kecematan mandau kabupaten Bengkalis.}

Dari tabel 4.2 dan gambar 4.1 menujukkan jumlah skor masing-masing indikator dari kompetensi kepribadian, dimana secara deskriptif dapat ditujukkan bahwa nilai (skor) dari indikator pertama $23,31 \%$, indikator kedua $26,31 \%$, indikator ketiga $28,12 \%$, dan indikator keempat $31,25 \%$. Data mengenai kompetensi kepribadian yaitu nilai skor 666 denagan persentase $40,05 \%$ menujukkan kompetensi kepribadian termasuk kategori tidak baik dakam rentang 20\%-40\%

Pengukuran terhadap kedisplinan TK di kecematan Mandau kabupaten bengkalis menggunakan 28 butir pertanyan. Skor tertinggi pertanyaan diberi 5 dan terendah diberi skor 1 serta disebarkan kepada 45 orang sampel.

Tabel 4.2 Skor Indikator Variabel Kedisiplinan

\begin{tabular}{|c|c|c|c|c|c|}
\hline No & Indikator & item & skor faktul & skor idel & perentense \\
\hline 1. & $\begin{array}{l}\text { Bertanggung } \\
\text { baik } \\
\text { Jawab }\end{array}$ & 5 & 45 & 190 & $95,74 \%$ \\
\hline & $\begin{array}{l}\text { Tempat waktu } \\
\text { cukup }\end{array}$ & 4 & 45 & 185 & $75,77 \%$ \\
\hline 3. & $\begin{array}{l}\text { Pelaksanan tugas } \\
\text { cukup }\end{array}$ & 3 & 45 & 179 & $75,37 \%$ \\
\hline & $\begin{array}{l}\text { Menguasai media } \\
\text { cukup }\end{array}$ & 2 & 45 & 143 & $70,42 \%$ \\
\hline & jumlah & 14 & 180 & 697 & $89,01 \%$ \\
\hline
\end{tabular}

Penyebaran distribusi frekuensi data kedisiplinan guru dapat disajikan dalam bentuk diagram batang, untuk lebih jelasnya dapat di lihat batang dibawah ini 


\section{Persentase kedisiplinan}

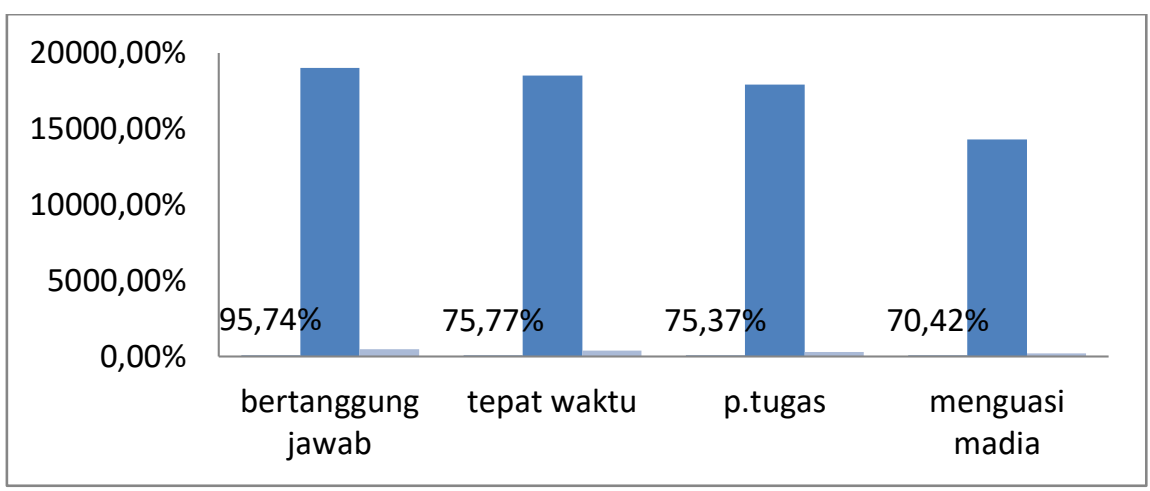

\section{Gambar 4.1 grafik Persentase Data Kedisiplinan guru TK Duri Kecematan Mandau Kabupaten Bengkalis.}

Dari gambar diatas menujukan jumlah skor masing-masing indikator dari kedisiplinan guru, dimana deskriptif dapat ditujukkan bahwa niaklai skor dari indikator pertama yaitu berbagi $95,74 \%$, indikator kedua tepat waktu persentase $75,77 \%$, indikator ketiga pelaksanan tugas persentase $75,37 \%$, indikator keempatan mengusai media persentase $70,42 \%$. Data mengenai kedisiplinan guru secara keseluruhan yaitu nilai skor 697 atau sekitar $89,01 \%$ menujukan bahwa kedisiplinan guru dalam termasuk kategori cukup baik dalam rentang 70\%-90\%.

\section{Uji prasyarat}

Uji normalitas menggunakan sampel kolmogorov-smimov dengan ketantuan yang telah digunakan sebagai berikut.

Tabel 4.5 hasil Uji Normalitas

\begin{tabular}{cccc}
\hline & & Kepribadian & kedisiplinan \\
\hline $\mathrm{N}$ & & 45 & 45 \\
Normal parameters & Mean & 88,5 & 80,8 \\
& Std. Deviation & 6.309 & 10,768 \\
Most Extreme Disfferences & Absolute & 200 & 957 \\
& & & \\
& Postive & 200 & 867 \\
Test Statistic & Negative & -140 & -867 \\
Asymp . sig.(2-tailed )a & & 200 & 179 \\
Test distrtisbution is Normal & & & \\
& & & \\
& & & \\
\hline
\end{tabular}

Dari hasil uji normalitas kolmogorof-smimov diatas dapat bahwa data kedua variabel normal. Syarat suatu variabel diakatakan nornal dalam distribusi datanya adalah memiliki signitifikasi 200>0,05. Dan untuk variabel kedisiplinan mempunyai disfikasi 179>0,05. Dapat dismpulkan bahwa untuk variabel terikat kedisiplinan ( Y) dan variabel kepribadian (X) berasal dari populasi normal pada taraf sigfikasi 0,05 maka variabel secara statistik telah berdistribusi secara normal dan layak digunakan sebagai penelitian. 


\section{Uji linieritas}

Tabel 4.6 hasil uji liniearitas

$\begin{array}{cccccccc} & & \begin{array}{l}\text { Sum } \\ \text { Squeres }\end{array} & \text { Df } & \text { Mean } & f & \text { Sig } \\ \text { Squar } & & & \\ \text { Kedisiplinan Betwee (combined } & 3.746 & 45 & 80,84 & 22 & 076 \\ \text { Guru } & \text { gruops } & \text { linerarity) } & 3.663 & 45 & 77,61 & 56 & 0,01 \\ & \text { Deviati on } & 10,768 & 45 & 81,37 & 58 & 0.56\end{array}$

From linerarit

Kepribadian Withim group

$88.66 \quad 45 \quad 88,56$

Total

$106,237 \quad 180$

Dua variabel dikatakan mempunyai hubungan liner apabila $p<0,05 \%$ berdasarkan table diatas, analisis data mangahasilkan nilai F 58 dengan sigfikasi 0,01 , karna $\mathrm{p}<5 \%$ dengan nilai signifikifikasi variabel bernilai 5\% maka dapat disimpulkan bahwa garis antara kompetensi lkepribadian dengan kedisiplinan guru di TKDuri kecamatan Mandau Kabupaten Bengkalis mempunyai hubungan liner. karna hasil menunjukkan bahwa sig $0,01<0,05$, sehingga dapat dilkatakan bahwa hubungan kedua variebal tersebut liner.

\section{Homogenetis}

Homogenetis ini dilakukan untuk mengetahui apakah data penelitian yang diperoleh homogen atau tidak. Pada suatu penelitian data tersebut homogen apabila $\mathrm{p}>0.05$. uji homogenitas dalam penelitian ini dapat dilihat pada tabel dibawah ini:

Tabel 4.7 Homogenetis

Levense statistic

$d f 1 \quad d f 2 \quad$ sig

173

$45 \quad 1$

625

Berdasarkan hasil uji analisis homogenitas, diperoleh nilai statistik, sebesar 173 dan nilai probilitas 173. karena nilai $\mathrm{P}>0,05(625>0,05)$ maka data adalah homogen.

\section{Uji Hipotesis}

Hipotesis untuk mengetahui data sesuai dengan hipotensi dan tujuan peneletian yaitu untuk mengetahui ada tidaknya Hubungan Kompetensi Kepribadian dengan Kedisiplinan guru di Tk Duri Kecamatan Mandau Kabupaten Bengkalis untuk.

\section{Hasil Chi Squer}

value $\quad D F \quad$ Asymptotic Significancez

Sig. (2.tailed)

\begin{tabular}{lccc}
\hline Pearson chi-squer & $3,746^{\mathrm{a}}$ & 1 & 053 \\
Likelihood Ratio & 3,800 & 1 & 102 \\
Linear by-liner & 3,663 & 1 & 0,56 \\
Association & & & \\
Nof Valid Cases & 45 & &
\end{tabular}

Dari tabel diatas diperoleh nilai Chi Squer sebesar 3,748 a dengan probilitas 0,053. Hal ini menujukkan bahwa terdapat Hubungan Kompetensi Kepribadian dengan Kedisiplinan guru di 
Tk Duri Kecematan Mandau Kabupaten Bengkalis. Nilai Chi Squer menujukan bahwa antara variabel Kompetensi Kepribadian dengan Kedisiplinan guru memilik hubungan negatif. Untuk menguji signifikasi Hubungan dapat diketahui melalui hasil analisis dengan Peorson Chi-Squer, dengan melihat nilai Chi-Squer yang diperoleh.

Koefisiensi Determinasi

\begin{tabular}{ccccc}
\hline & & & Adjusted $R$ Squer & Std.Error the Estimate \\
Model & $\mathrm{R}$ & R Squer & & \\
1 & 625 & 354 & 354 & 1,605 \\
\hline
\end{tabular}

Berdasarkan tabel diatas koefisiensi determinasi yang dihasilkan adalah sebesar 0,354 artinya 35,4\% variabel kompetensi kepribadian menentukan kedisiplinan. Sedangkan arah postif karena $\mathrm{r}$ postif, berarti semakin tinggi kompetensi kepribadian maka semakin tinggi kedisiplinan guru.

\begin{tabular}{lcccccc} 
hasil uji “t”" \\
\hline \multicolumn{3}{c}{ Unstandardized Coefficients } & \multicolumn{3}{c}{ Standardized } \\
Model & \multicolumn{3}{c}{ B } & std Error & beta & t $\quad$ sig \\
1 & constant & 3,081 & 940 & & 200 \\
& $\begin{array}{l}\text { kompetensi } \\
\text { kepribadian }\end{array}$ & 968 & 354 & 625 & 3.361 & 00
\end{tabular}

Untuk membuktikan signifikasikan hubungan kompetensi kepribadian dengan kedisiplinan dapat dilakukan uji t berdasarkan perhitungan yang diperoleh nilai sebesar 3.361 dengan sigfikasi 0,000 diperoleh nilai 5\% sebesar 88,56\%.

Berdasarkan data tabel diatas, dapat dilihat koefisien korelasi sebesar 0,354 yang terletak pada rentang 0354. -0,599 dengan kategori sedang. Artinya terdapat hubungan kompentensi kepribdadian dengan kedisiplinan Guru TK. Sedangkan arah hubungan adalah positif karena nilai $r$ positif, berarti semakin tinggi. Hubungan Kompetensi kepribadian dengan kedisiplinan guru.

Koefisien determinasi yang dihasilkan adalah sebesar $r^{2}=0,625$ dengan $p=0,000(p>0,05)$. Artinya 35,4\% variabel hubungan kompentensi kepribdadian dengan kedisiplinan guru.

Untuk membuktikan signifikan hubungan kompentensi kepribdadian dengan kedisiplinan guru dilakukan "uji t". Berdasarkan kepentingan, diperoleh nilai $t_{\text {hitung }}$ sebesar 3,361 dengan signifikansi 0,000. Diperoleh nilai $\mathrm{t}_{\text {table }}$ dengan $\mathrm{dk}=\mathrm{n}-2=53-2=56$ pada taraf signifikansi 5\% (2-tailed) sebesar 10.768 Dengan demikian diketahui $t_{\text {hitung }}(3.081)>t_{\text {tabel }}(1,605)$ atau signifikansi $(0,000)<5 \%(0,05)$. Dapat diartikan bahwa persepsi guru hubungan komeptensi kepribadian signifikan terhadap kedisiplinan guru.

Berdasarkan hasil penelitian pada variabel hubungan kompentensi kepribadian dengan kedisiplinan guru, perolehan skor dari subjek penelitian mendapatkan hasil bahwa hubungan kompentensi kepribdadian dengan kedisiplinan guru TK Duri Se-Kecamatan Mandau berada pada kategori sedang yaitu dari 45 subjek penelitian diperoleh dari 10 sekolah atau 89,5\% tingkat kompentensi kepribdadian dengan kedisiplinan guru sedang.

Data mengenai kedisiplinan guru, dimana secara deskriptif dapat ditujukkan bahwa nilai (Skor) dari indikator pertama 95.74\%, indikator kedua 75,77\%, indikator ketiga 75,37\% dan indikator keempat $70,42 \%$. Data mengenai kedisiplinan guru secara keseluruhan yaitu nilai skornya 697 atau sekitar 89,05\% menunjukkan bahwa kedisiplinan dalam ketagori cukup baik dalam rentang $70 \%-80 \%$.

Berdasarkan kuesioner yang telah diisi oleh 45 orang merespon kompetensi kepribadian guru di TK Duri Kecamatan Mandau Kabupaten Bengkalis. Yang diperoleh data yaitu,dengan ratarata yang diperoleh adalah $30,05 \%$, indikator pertama presentase $23,31 \%$, indikator kedua 
presentase $26,62 \%$, indikator ketiga presentase $28,12 \%$, dan indikator keempatan pertanse $31,25 \%$.

Kompetensi kepribadian ini adalah salah satu kemampuan personal yang harus memiliki oleh guru profesional dengan cara mencermikan kepribadian yang baik, sedangkan kedisiplinan didefinisikan sebagai suatu sikap menghormati, menghargai, patuh, dan taat terhadap peraturanperaturan yang berlaku baik yang tertulis maupun tidak tertulis.

Nurhalimah berpendapat bahwa kompetensi kepribadian guru harus menujukan perilaku dewasa dalam mengahadapi peserta didik, guru menujukan dari sebagai pribadi yang ceria, sabar, lemah lembut, bertutur kata yang baik, mongontrol, guru yang menujukan tanggung jawab yang tinggi pada pesrta didik menyelesaikan pekerjaan sampai selesai, menjalakan tugas dengai sebaik mungkin, mematahui aturan yang ada disekolah, dan guru memiliki etos kerja yang baik pada lingkungan, bahan ajar sebelum kegiatan pembelajaran.

Menurut Syamsul Bachir Thalid (2010) kompetensi kepribadian merupakan personal yang mencerminkan kepribadian yang stabil, dewasa, arif, berwibawa, mejadi teladan bagi peserta didik dan berakhlak.

Rosa karmila dkk, menjelaskan kedisiplinan merupakan sifat dari pertanggungjawaban inividu untuk melakasankan segala sesuatunya tepat waktu. Jika tidak disiplin maka pekerjaannya yang di kerjakan tidakan selesai tepat waktu.

Mulyasa menyatakan bhawa disiplinan mengadung makna bahwa guru menyadari, memahami, dan mematahui berbagi peraturan dan tata tertib secara konsisten dan profesional karena mereka bertugas untuk mendisiplinakan para pesrta didiknya, okleh karenanya dalam menamankan disiplinan guru harus memulai dari dirinya sendiri.

\section{UCAPAN TERIMA KASIH}

Tim peneliti mengucapkan terima kasih kepada Universitas Riau dan Program Studi Pendidikan Guru Pendidikan Anak Usia Dini yang telah memberi dukungan terhadap terlaksananya penelitian ini. Tim peneliti juga mengucapkan terima kasih kepada Pengelola Jurnal Review Pendidikan dan Pengejaran (JRPP) yang telah memberi review dan masukan atas terbitnya artikel ini.

\section{SIMPULAN}

Berdasarkan hasil penelitian yang telah dilakukan, dapat simpulkan bahwa terdapat hubungan negatif yang signifikan antara kompetensi kepribadian guru dengan kedisiplinan guru yang terjadi di di TK Duri Kecematan Mandau Kabupaten Bengkalis.

\section{DAFTAR PUSTAKA}

Arikunto.Suharsimi.2006 .Prosedur Penelitian Suatu Pendekatan Praktis.Jakarta: Edisi Revisi.

Janawi. 2011. Kompetensi Guru.Alfabeta.

Purwanto. 2013.Metode Penelitian Pendidikan (Pedekatan, kuantitatif, kualitatif, dan R\&D). Bandung:Alfabeta.

Sugiyono. 2013. Metode Penelitian Adminstrasi. Bandung: Alfabeta

Hasibuan, S.P Malayu. 2005. Manajemen Sumber Daya Manusia. Jakarta: Bumi Aksara

Soetjipto.2007. Seri Bimbangan Organisasi dan Adimiinistrasi Bimbingan dan Konseling $d i$ Sekolah. Surabaya: Departemen Pendidikan Nasional RI.

Undang-Undang Republik Indonesia Nomor 20 Tahun 2003. Sistem Nasional Jakarta:

Departemen Pendidikan Nasional RI.

Walgito. 2007. Psikologi Kelompok. Jakarta: Andi offset.

Uno,Hamzah. 2012. Orientasi Baru dalam Psikologi Pembelajaran. Jakarta: Bumi Aksara.

Kunandar. 2007. Guru Profesional: Implemetasi Kurikulum Tingkat Satuan $\quad$ Pendidikan (

KTPS) dan Sukses dalam Sertifikasi Guru Jakarta: Rajagrafindo persada.

Undang-Undang Republik Indonesia N0.14 Tahun 2005. Tentang Guru dan dosen. 
Sulistyowati, Indah. 2010. Pengaruh Profitabilitasi,Leverage dan Growth $\quad$ Terhadap Kebijakan Divided dengan Good Corporate Sebagai Variable Intervening.Simposium Nasional Akuntansi (SNA) XII. Purwokerto.

Ali, Muhammad, 2002. Guru dalam Proses Belajar dan Mengajar. Bandung: Sinar Baru Algensindo

Iskandar. 2012. Psikologi Pendidikan (Sebuah Orientasi baru). Jakarta: Bumi Askara.

Syahrum, Salim. 2016. Metode Penelitian Kuatitafi. Bandung: Cita Pustaka Media.

Mulyasa, E. 2007.Standar Kompetensi dan Sertifikasi Guru.Bandung: PT. Remaja Rosdakarya Mussen. 2012. Essential of Child Development \&Porsonality. New York: Haper.

Sugiyono. 2014.Statistika Untuk Penelitian. Bandung: Cv Alfabeta

Sugiyono. 2013. Metode Penelitian Pendidikan Pendekatan Kuantitatif, Kualitatif, dan R\&D. Alfabeta: Bandung.

Budi ningsih, A. 2009. Belajar dan Pembelajaran. Jakarta: Rineka ciptra. 